\title{
Long-Term Effects of Laparoscopic Sleeve Gastrectomy and Roux-en-Y Gastric Bypass on Body Composition and Bone Mass Density
}

\author{
Julian Bühler ${ }^{a-c}$ Silvan Rast ${ }^{a, b} \quad$ Christoph Beglinger ${ }^{b}$ Ralph Peterli ${ }^{a-c}$ \\ Thomas Peters $^{d}$ Martina Gebhart ${ }^{d}$ Anne Christin Meyer-Gerspach ${ }^{\mathrm{a}}$ b \\ Bettina Karin Wölnerhanssen ${ }^{a, b}$ \\ ${ }^{a}$ St. Clara Research Ltd., St. Claraspital, Basel, Switzerland; b University of Basel, Basel, Switzerland; ' Clarunis, \\ Department of Visceral Surgery, University Centre for Gastrointestinal and Liver Diseases, St. Clara Hospital and \\ University Hospital Basel, Basel, Switzerland; ${ }^{d}$ Endocrinology and Nutrition, St. Claraspital, Basel, Switzerland
}

\section{Keywords}

Bariatric surgery · Sleeve gastrectomy · Gastric bypass · Bone density · Dual-energy X-ray absorptiometry · Body composition

\begin{abstract}
Background: Currently, the two most common bariatric procedures are laparoscopic sleeve gastrectomy (LSG) and laparoscopic Roux-en-Y gastric bypass (LRYGB). Long-term data comparing the two interventions in terms of their effect on body composition and bone mass density (BMD) are scarce. Objective: The aim of this study was to assess body composition and BMD at least 5 years after LSG and LRYGB. Setting: Department of Endocrinology and Nutrition, St. Claraspital Basel and St. Clara Research Ltd., Basel, Switzerland. Methods: Bariatric patients at least 5 years after surgery (LSG or LRYGB) were recruited, and body composition and BMD were measured by means of dual-energy X-ray absorptiometry. Data from body composition before surgery were included in the analysis. Blood samples were taken for determination of plasma calcium, parathyroid hormone, vitamin $\mathrm{D}_{3}$, alkaline phosphatase, and C-terminal telopeptide, and
\end{abstract}

karger@karger.com www.karger.com/ofa

Karger $\frac{1}{\%}$

GOPEN ACCESS
(C) 2020 The Author(s)

Published by S. Karger AG, Basel

This article is licensed under the Creative Commons AttributionNonCommercial-NoDerivatives 4.0 International License (CC BYNC-ND) (http://www.karger.com/Services/OpenAccessLicense). Usage and distribution for commercial purposes as well as any distribution of modified material requires written permission. the individual risk for osteoporotic fracture assessed by the Fracture Risk Assessment Tool score was calculated. After surgery, all patients received multivitamins, vitamin $D_{3}$, and zinc. In addition, LRYGB patients were prescribed calcium. Results: A total of 142 patients were included, 72 LSG and 70 LRYGB, before surgery: median body mass index 43.1, median age 45.5 years, $62.7 \%$ females. Follow-up after a median of 6.7 years. For LRYGB, the percentage total weight loss at follow-up was $26.3 \%$ and for LSG $24.1 \%$ ( $p=0.243$ ). LRYGB led to a slightly lower fat percentage in body composition. At follow-up, $45 \%$ of both groups had a T score at the femoral neck below -1 , indicating osteopenia. No clinically relevant difference in BMD was found between the groups. Conclusions: At 6.7 years after surgery, no difference in body composition and BMD between LRYGB and LSG was found. Deficiencies and bone loss remain an issue after both interventions and should be monitored.

(C) 2020 The Author(s)

Published by S. Karger AG, Basel

Julian Bühler and Silvan Rast shared first authorship, Anne Christin Meyer-Gerspach and Bettina Karin Wölnerhanssen shared shared last authorship. 


\section{Introduction}

Doubtless, obesity surgery is a drastic approach that is not without risks; but these are usually outweighed by the risks of morbid obesity, especially when considering the increasingly safe bariatric operations. However, potential long-term adverse effects of bariatric surgery such as malnutrition and micronutrient deficiencies must be studied in detail. Under ideal circumstances, weight loss would be limited to loss of fat mass with complete preservation of lean mass; however, weight loss is always a combination of both [1]. Maintenance or enhancement of lean mass is not only important for muscular strength and endurance, but is also associated with improved metabolic outcome reflected for instance in a higher insulin sensitivity [2]. In addition, the regional distribution of fat is of importance: central adiposity is an independent marker of insulin resistance in obesity and is a major contributor to metabolic complications [3]. Laparoscopic Roux-en-Y gastric bypass (LRYGB) is often described as more potent in the amelioration of various comorbidities - such as type 2 diabetes mellitus, dyslipidemia, and hypertension - compared to laparoscopic sleeve gastrectomy (LSG) [4-7]. The differences in metabolic outcome between these two operations might also be mirrored in their effect on body composition and body shape. Although several studies have examined the effects of LRYGB on body composition [8-10], only a few studies have compared LRYGB with LSG, and mostly follow-up is no longer than 3 years after surgery [11-15].

Osteoporotic fractures are a critical public health problem worldwide [16]. Approximately $40 \%$ of postmenopausal women experience at least one fracture in their lifetime [17-19]. Fractures can have devastating consequences, including functional decline, prolonged disability, and death [20]. With longevity increasing globally, the potentially high cumulative rate of osteoporosis and fractures, and the associated excess disability and mortality, will lead to an increase in social and economic burden $[21,22]$. Osteoporosis is a silent disease, and bone loss occurs without any signs or symptoms. Therefore, fracture prediction and monitoring of risk groups such as bariatric patients becomes critically important. Fracture risk seems to be increased after bariatric surgery [23]. Bone loss and the development of osteoporosis have been shown after malabsorptive operations like biliopancreatic diversion, but also LRYGB [24, 25]. Nonmalabsorptive bariatric operations like the gastric banding procedure seem to affect bone health much less than LRYGB [26]. Little is known about the risk of osteoporosis after LSG.
The aim of this study was to assess the body composition and the bone mass density (BMD) at least 5 years after LSG or LRYGB. The hypothesis was that in LRYGB patients a lower percentage of fat and a lower BMD (documented by a lower $\mathrm{T}$ score at the femoral neck) would be observed compared to LSG at $>5$ years after surgery.

\section{Methodology}

The study protocol was approved by the local ethical committee and registered at the clinical trials registry of the National Institutes of Health (NCT03410459). To summarize, the trial was designed as a two-group, nonrandomized, single-center study involving 142 morbidly obese consecutive patients, in which the outcomes of LSG were compared to those of LRYGB.

Baseline health-related data could be retrieved from patient records. At the follow-up, patients were seen in our outpatient clinic and examined according to the study protocol.

Body composition and BMD were analyzed by dual-energy Xray absorptiometry (DEXA) using a Hologic QDR 4500 A scanner (Hologic Inc., Bedford, MA, USA). BMD was measured at the femoral neck, hip, and lumbar spine $\left(\mathrm{L}_{1-4}\right)$ to grade the severity of low bone density and osteoporosis by the lowest T score. A T score of -1.0 or higher is categorized as normal BMD, while a $\mathrm{T}$ score between -1.0 and -2.5 means low bone density (osteopenia), and a $\mathrm{T}$ score of -2.5 or lower is considered diagnostic of osteoporosis.

The Fracture Risk Assessment Tool (FRAX) computes the 10year probability of major osteoporotic fracture (a composite of hip, humerus, forearm, and clinical vertebral fractures) and hip fracture [27]. High risk of osteoporotic fracture is defined as a 10-year probability of $\geq 20 \%$ for major osteoporotic fractures or $\geq 3 \%$ for hip fractures. The FRAX risk score comprises common risk factors for osteoporotic fractures including smoking, previous fracture, hip fracture in parents, rheumatoid arthritis, alcohol abuse $(>3$ units/day), and secondary osteoporosis. Secondary osteoporosis is defined as presence of either diabetes, osteogenesis imperfecta, hypothyroidism, hypogonadism or early menopause, chronic malabsorption, and chronic liver disease. C-terminal telopeptide (CTX) - a marker for bone turnover - was measured by a commercially available automated chemiluminescence immunoassay [28].

After surgery, all patients received multivitamins alternating with high-dose vitamin B group supplementation and $10 \mathrm{mg}$ zinc on a daily basis. While LRYGB patients were prescribed $500 \mathrm{mg}$ calcium and $800 \mathrm{IU}$ vitamin $\mathrm{D}_{3}$ /day, LSG patients were recommended vitamin $\mathrm{D}_{3}$ supplementation without calcium.

Statistical analysis used R (R Core Team) [29] with package knitr [30] for reporting. In baseline tables, Wilcoxon tests for between-group differences of continuous variables were used, and Kruskall-Wallis tests for categorical variables. By preference, between-group treatment effects are reported with $95 \%$ confidence intervals; $p$ values are given only for prespecified end points [31]. Confidence intervals were computed from contrast tables of linear models or mixed-effect models [32]. The primary end point was computed with patient age at time of surgery as a linear covariable. In addition, tests for other confounding variables were done using Bayesian model averaging [33-35], which accounts for the model uncertainty inherent in the variable selection problem by averag- 


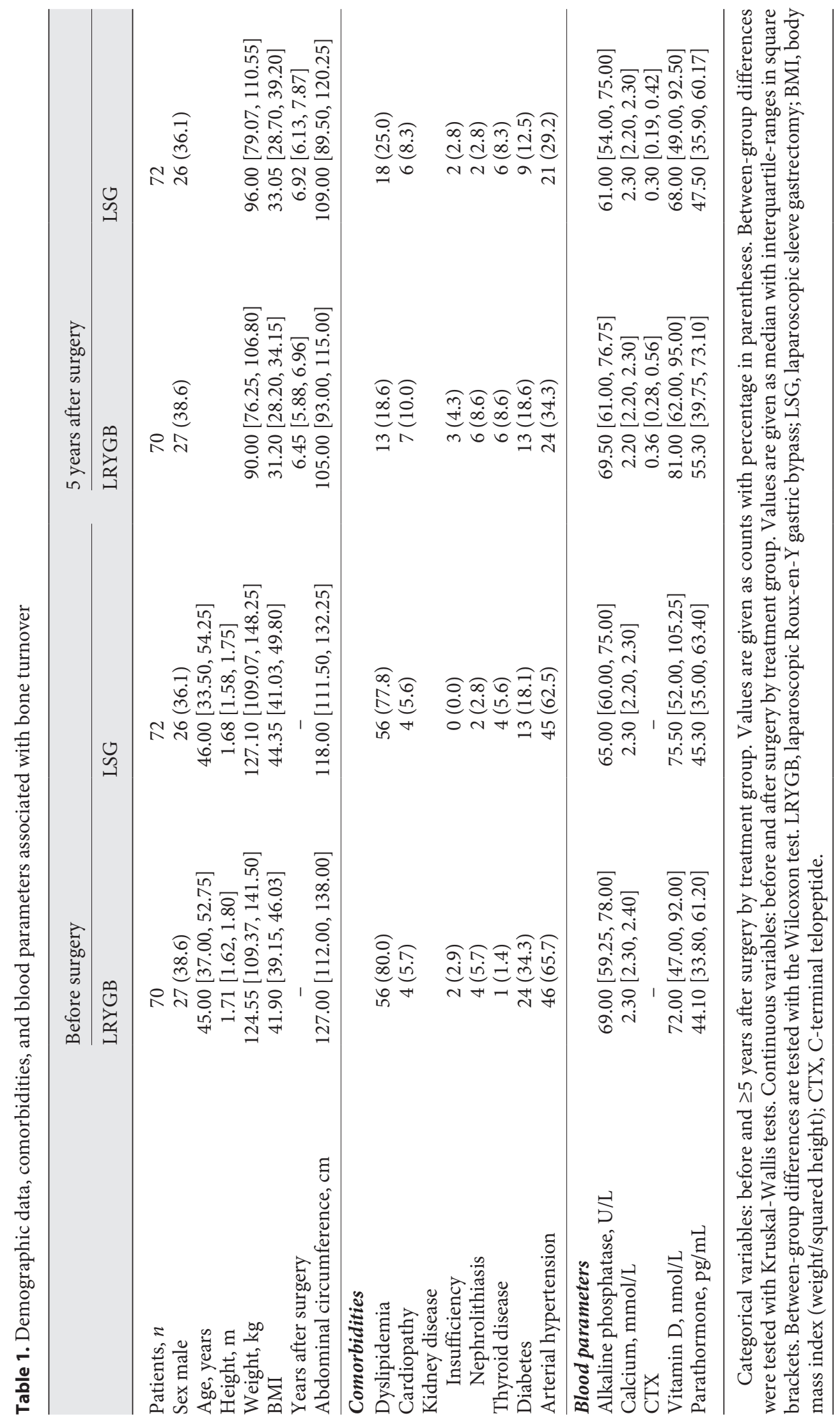




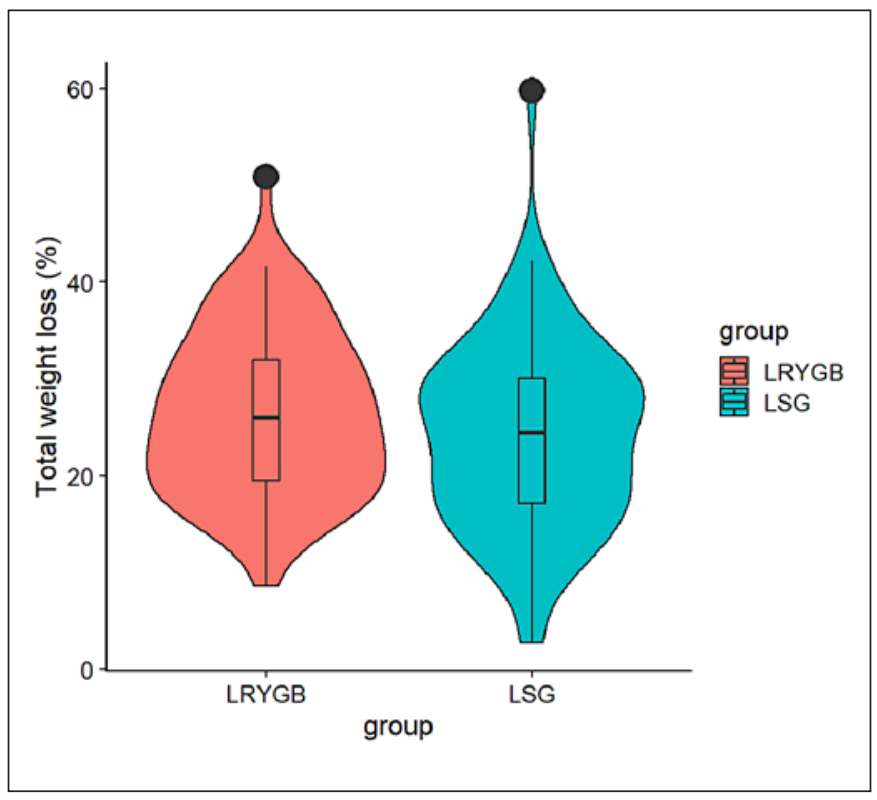

Fig. 1. Violin plot showing the distribution of percent total weight loss at follow-up. Outliers are marked by a thick dot. Percent total weight loss is defined as $\% \mathrm{TWL}=([$ initial weight $]-$ [weight at follow-up $]) /([$ initial weight $]) \times 100$. LRYGB, laparoscopic Roux-enY gastric bypass; LSG, laparoscopic sleeve gastrectomy.

ing over the best models in the model class according to approximate posterior model probability. FRAX scores are not defined for patients younger than 40 years and with a body weight above 125 $\mathrm{kg}$, so about one third of the FRAX scores are censored. To avoid bias, censored Bayesian statistic was used as provided by the $\mathrm{R}$ package brms [36]. Since FRAX scores have approximate log-normal distribution, the logarithms of the scores were evaluated. As a consequence, comparisons between groups were given as ratios instead of differences. Whether bariatric interventions such as LRYGB, which are at least malabsorptive for minerals, should qualify for the presence of chronic malabsorption when using the FRAX score is not defined. In this study, LRYGB was not automatically considered as "malabsorption" for the calculation of the FRAX score.

\section{Results}

Patients were seen before and after a median of 6.7 years, with an interquartile range of 6.1-6.7 years (range: 5-13 years). Regarding age and gender distribution, the two groups were comparable at baseline. A higher prevalence of diabetes was seen in the LRYGB group ( $n=13 \mathrm{vs.}$ $24, p=0.044$; Table 1 ), and body mass index (BMI) was also significantly different: the lower interquartile range was similar for both groups, but the upper quartile was higher for the LSG group. Patients in the LSG group had higher values and were more heterogenous in BMI.

\section{Weight Loss}

For patients at the age of 45 years, i.e. the population median, mean weight loss was higher by $2.2 \%$ for the LRYGB group compared to the LSG group. The $95 \%$ confidence interval of the difference in weight loss was -0.7 to $5.1 \%$, which is compatible with a value of 0 . For LRYGB, percentage total weight loss at follow-up was $26.3 \%$ (24.2, $28.4)$, and for LSG $24.1 \%(22.1,26.1), p=0.243$. For patients at the age of 35 years, i.e. the population lower quartile, mean percentage weight loss was higher by $3.1 \%$ (95\% confidence interval, CI, -0.5 to 6.7 ) for the LRYGB group compared to LSG. For patients at the age of 53 years, i.e. the population upper quartile, mean percentage weight loss was higher by $1.5 \%$ (95\% CI -2 to 5$)$ for the LRYGB group compared to LSG (Fig. 1).

\section{Comorbidities}

More patients were diabetic at baseline in the LRYGB group compared to the LSG group. A small fraction of the patients who were nondiabetic before surgery developed non-insulin-dependent diabetes until followup (LRYGB: $n=4$, LSG $n=3$ ). For both groups, about half of the patients who were nondiabetic before surgery were in remission at follow-up (LRYGB: $n=15 / 24$, $62.5 \%$; LSG: $n=7 / 13,53.8 \%)$. A difference in remission rate between the groups for diabetes could not be found. In both groups, most patients had $d y$ slipidemia at baseline (LRYGB: $n=56 / 70$, LSG: $n=56 / 72$ ). Few patients developed dyslipidemia during the study period (LRYGB: $n=1$, LSG: $n=2$ ). Most patients with dyslipidemia at baseline experienced remission (LRYGB: $n=$ 44/56, 78.6\%; LSG: $n=40 / 56,71.4 \%)$. A difference in remission rate between the groups of dyslipidemia could not be found.

\section{Body Composition}

For 115 patients, body scan data with values for the total mass at two visits were available. While percent fat was similar at baseline in both groups, at follow-up slightly lower values were found in the LRYGB group compared to the LSG group. For a patient of median age, LSG was found to be slightly less effective in reducing fat percentage compared to LRYGB, and lean mass loss was higher in LSG ( $p=0.059)$ (Table 2, Fig. 2, 3). The trunkto-leg fat ratio was similar at baseline in both groups; at the follow-up, slightly lower values were found in the LRYGB group compared to the LSG group (n.s.). 
Fig. 2. Difference in weight loss between treatment groups for a patient with median age. Mean and $95 \%$ confidence intervals for the difference between groups are shown for all quantities with a unit of kilograms. Percent fat and trunk-to-leg fat ratio are excluded. Bars that do not overlap the vertical line are significant at the $5 \%$ level. LRYGB, laparoscopic Roux-en-Y gastric bypass; LSG, laparoscopic sleeve gastrectomy.

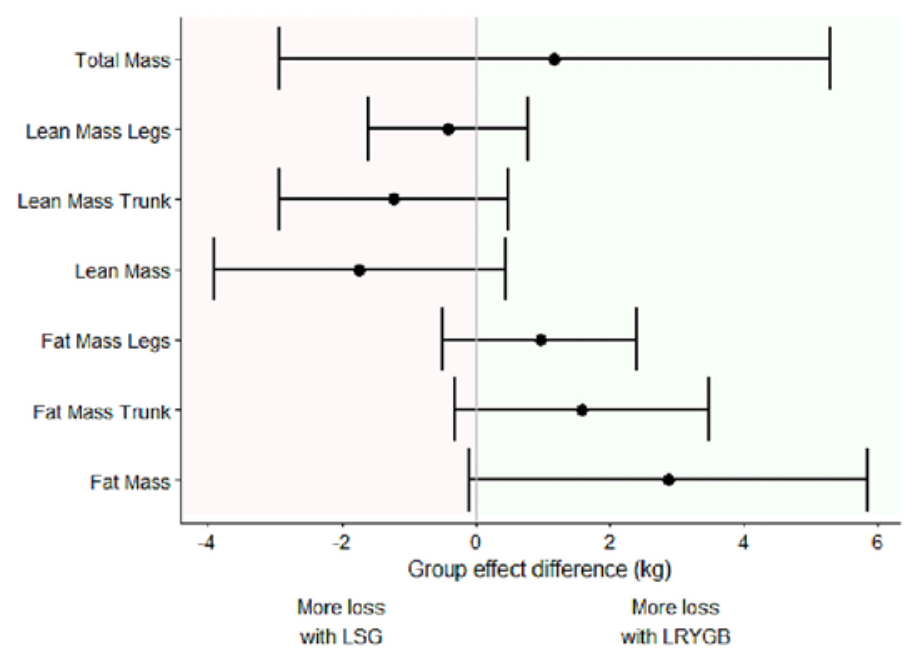

Table 2. Body composition before and at 5 years after surgery

\begin{tabular}{|c|c|c|c|c|c|c|}
\hline & \multicolumn{3}{|l|}{ Before surgery } & \multicolumn{3}{|l|}{ After surgery } \\
\hline & LRYGB & LSG & SMD & LRYGB & LSG & SMD \\
\hline Total mass, $\mathrm{kg}$ & $119.30[107.35,133.60]$ & $123.25[103.62,138.30]$ & 0.133 & $85.30[72.85,102.95]$ & $91.65[75.50,105.97]$ & 0.222 \\
\hline Fat, $\mathrm{kg}$ & $49.20[44.90,56.65]$ & $51.45[45.62,58.67]$ & 0.109 & $34.80[28.85,41.40]$ & $38.95[31.52,46.30]$ & 0.445 \\
\hline Fat, \% & $44.50[39.95,46.60]$ & $43.65[39.25,46.58]$ & 0.043 & $40.80[36.55,45.35]$ & $44.10[38.35,47.70]$ & 0.414 \\
\hline Fat trunk, kg & $24.70[21.15,28.20]$ & $26.50[21.40,30.62]$ & 0.408 & $16.90[13.20,20.95]$ & $20.80[16.15,23.75]$ & 0.487 \\
\hline Fat left leg, kg & $9.20[7.00,10.75]$ & $8.05[7.32,10.88]$ & 0.034 & $6.20[5.35,7.40]$ & $6.40[5.50,8.33]$ & 0.302 \\
\hline Fat right leg, $\mathrm{kg}$ & $9.50[7.25,10.90]$ & $8.75[7.73,11.12]$ & 0.003 & $6.20[5.40,7.20]$ & $6.25[5.50,8.42]$ & 0.228 \\
\hline Trunk-to-leg fat ratio & $1.39[1.08,1.71]$ & $1.32[1.08,1.75]$ & 0.017 & $1.35[1.10,1.70]$ & $1.50[1.17,1.83]$ & 0.158 \\
\hline Lean mass, $\mathrm{kg}$ & $63.40[55.90,74.40]$ & $61.80[56.62,78.90]$ & 0.117 & $45.30[41.45,59.10]$ & $47.85[40.62,55.85]$ & 0.014 \\
\hline BMC, g & $2,394.50[2,159.00,2,735.75]$ & $2,258.00[2,122.00,2,727.00]$ & 0.180 & $2,324.00[2,059.50,2,742.25]$ & $2,323.00[2,107.50,2,877.50]$ & 0.060 \\
\hline Lean mass and BMC trunk, $\mathrm{kg}$ & $33.70[30.75,38.70]$ & $34.05[30.02,41.40]$ & 0.136 & $24.50[22.45,32.05]$ & $25.45[21.85,28.72]$ & 0.037 \\
\hline Lean mass and BMC left leg, $\mathrm{kg}$ & $10.80[9.20,12.45]$ & $10.50[9.22,12.90]$ & 0.143 & $7.80[7.00,9.75]$ & $8.65[7.00,10.00]$ & 0.125 \\
\hline Lean mass and $\mathrm{BMC}$ right leg, $\mathrm{kg}$ & $10.90[9.65,13.50]$ & $10.85[9.50,13.17]$ & 0.084 & $8.10[6.90,10.00]$ & $8.40[6.90,9.95]$ & 0.023 \\
\hline
\end{tabular}

Continuous variables: before and $\geq 5$ years after surgery by treatment group. Values are given as median with interquartile-ranges in square brackets. Between-group differences are tested with the Wilcoxon test. LRYGB, laparoscopic Roux-en-Y gastric bypass; LSG, laparoscopic sleeve gastrectomy; BMC, bone mineral content; SMD, standardized mean difference between the treatment groups.

Bone mineral content (BMC) was measured at baseline and at follow-up in 62 LRYGB and 52 LSG patients. For the LRYGB group, the mean BMC at baseline was $2,468 \mathrm{~g}$. Baseline BMC for the LSG group was lower by 68 $\mathrm{g}$, with a CI of the difference of -249 to $113 \mathrm{~g}$. For LRYGB, $\mathrm{BMC}$ decreased by $8.5 \mathrm{~g} /$ year, corresponding to $-60 \mathrm{~g}$ in 7 years $(p=0.056)$. In the LSG group, the BMC decrease was less by $8.4 \mathrm{~g} /$ year, resulting in almost no change of 0.1 g/year, with a signed $95 \%$ CI of the difference of -4 to 21 $\mathrm{g} /$ year. The increase per 7 years in BMC was lower by 58.8 $\mathrm{g}$ in the LSG group, with a signed $95 \% \mathrm{CI}$ of the difference of -28 to $146 \mathrm{~g}$. Only small changes in both groups were observed, and a difference between the groups could not be found.

\section{Bone Mass Density}

At follow-up, the median $\mathrm{T}$ score at the femoral neck was slightly lower for LRYGB $(-0.75[-1.60,-0.30]$ vs. LSG $-0.60[-1.37,0.10])$. In the whole cohort, 3 patients had a T score of the femoral neck below -2.5 (osteoporosis; 1 patient of the LRYGB group and 2 patients of the LSG group). A T score at the femoral neck between -1 and -2.5 (osteopenia) was found in 30/72 (41.6\%) LSG and $31 / 70$ (44.3\%) LRYGB patients. 
Fig. 3. Distribution of the parameters of the whole-body scan displayed as violin plots. LRYGB, laparoscopic Roux-en-Y gastric bypass; LSG, laparoscopic sleeve gastrectomy; T/L fat ratio, trunk-to-leg fat ratio.

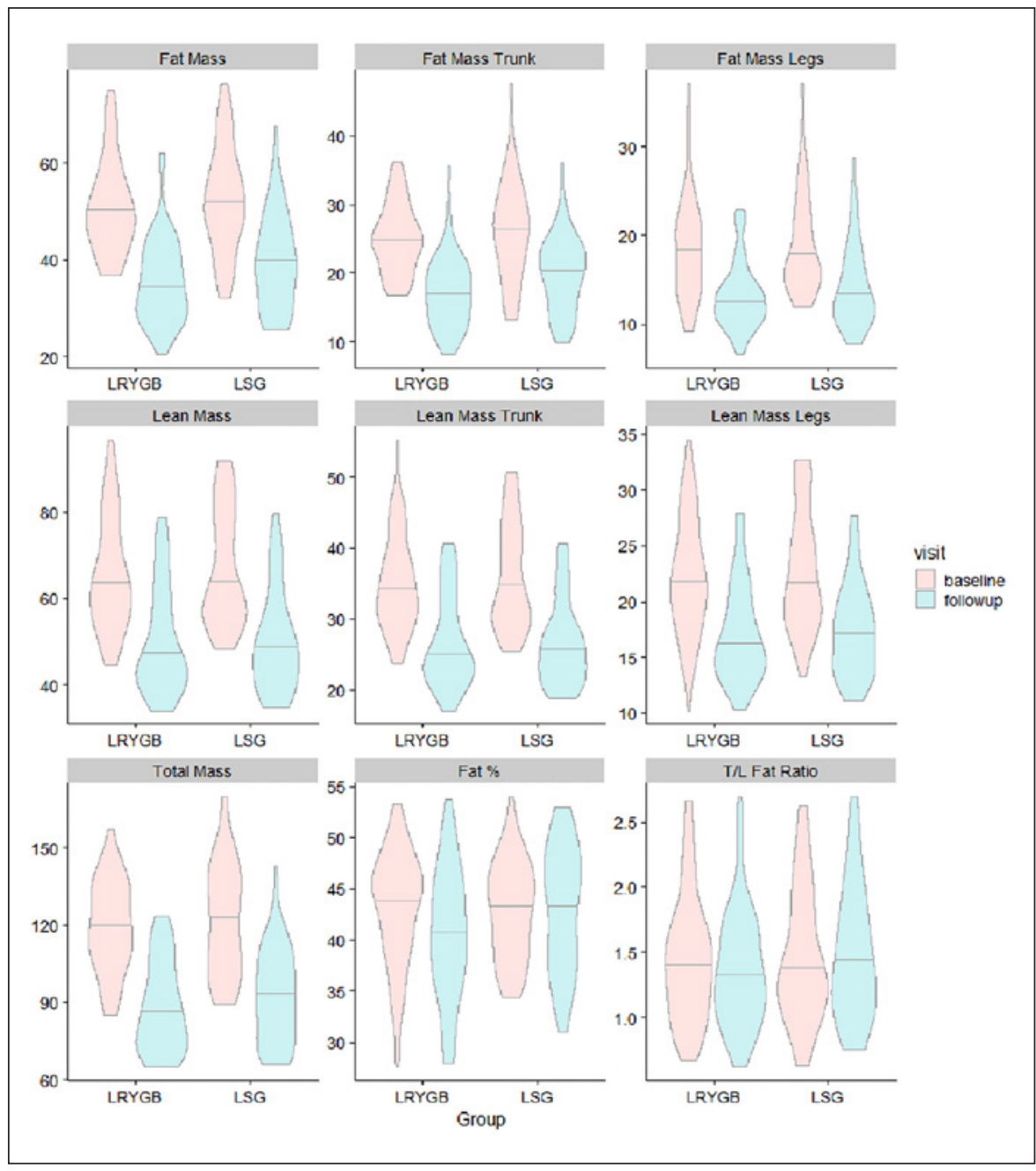

At follow-up, the median T score at the spine was -0.42 $(-1.30,0.97)$ for LRYGB and $-0.40(-1.00,0.80)$ for LSG. In the whole cohort, 8 patients had a $\mathrm{T}$ score of the spine below -2.5 ( 4 patients of the LRYGB group and 4 patients of the LSG group). A T score at the spine between -1 and -2.5 (osteopenia) was found in 19/72 (26.4\%) of LSG patients and in 25/70 (35.7\%) of LRYGB patients.

\section{Use of Supplements and Medication at Follow-Up}

While the use of vitamin $\mathrm{D}_{3}$ (LRYGB: $81.4 \%$, LSG: $77.8 \%$ ), vitamin $B_{12}$ (LRYGB: $37.1 \%$, LSG: $30.6 \%$ ), and multivitamins (LRYGB: 85.7\%, LSG: 79.2\%) was similar in the two groups, the fraction of patients receiving calcium supplementation was much higher in the LRYGB group due to the hospital policy to routinely substitute LRYGB with calcium (LRYGB: 57.1\%, LSG: $12.5 \%$ ). The intake of nonsteroidal anti-inflammatory drugs (LRYGB:
10.0\%, LSG: 16.7\%) and corticosteroids (LRYGB: 8.6\%, LSG: $9.7 \%$ ) was not different between the groups, while the fraction of patients taking proton pump inhibitors (PPIs) was much higher in the LSG group (LRYGB: 24.3\%, LSG: 52.8\%) (Table 3).

\section{Plasma Concentrations of Parathyroid Hormone,} Alkaline Phosphatase, Calcium, Vitamin D, and CTX At baseline no difference between the two groups could be found for levels of plasma parathyroid hormone (PTH), vitamin $\mathrm{D}_{3}$, calcium, and alkaline phosphatase. At follow-up, median PTH, alkaline phosphatase, and vita$\min \mathrm{D}_{3}$ levels were slightly higher in LRYGB patients (Table 1). In the LRYGB group, 20 (28.6\%) and in the LSG group $11(15.3 \%)$ patients had a PTH concentration above $65 \mathrm{pg} / \mathrm{mL}$ (indicating secondary hyperparathyroidism), while calcium levels were within the normal 
Table 3. Intake of medication and supplements, and risk factors for development of osteoporosis at $>5$ years after surgery

\begin{tabular}{lll}
\hline & LRYGB & LSG \\
\hline $\begin{array}{ll}\text { Medication } \\
\text { Glucocorticoids }{ }^{\mathrm{a}}\end{array}$ & $7(9.6)$ & $7(9.7)$ \\
NSAIDS & $7(10.0)$ & $12(16.7)$ \\
PPI & $17(24.3)$ & $38(52.8)$ \\
\hline Supplements & & \\
Vitamin $\mathrm{D}_{3}$ & $57(81.4)$ & $56(77.8)$ \\
Calcium & $40(57.1)$ & $9(12.5)$ \\
Multivitamin & $60(85.7)$ & $57(79.2)$ \\
Vitamin $B_{12}$ & $26(37.1)$ & $22(30.6)$ \\
\hline Risk factors & & \\
Current smoking & $15(21.4)$ & $20(27.8)$ \\
Alcohol: $\geq 3$ units/day & $8(11.4)$ & $1(1.4)$ \\
Previous fracture & $4(5.7)$ & $1(1.4)$ \\
Parent fractured hip & $2(2.9)$ & $7(9.7)$ \\
Rheumatoid arthritis & $1(1.4)$ & $4(5.6)$ \\
Secondary osteoporosis & $20(28.6)$ & $17(23.6)$ \\
\hline Bone density & & \\
Bone mineral content & $2,324.00[2,059.50,2,742.25]$ & $2323.00[2,107.50,2,877.50]$ \\
T score at femoral neck & $-0.75[-1.60,-0.30]$ & $-0.60[-1.37,0.10]$ \\
T score at spine & $-0.42[-1.30,0.97]$ & $-0.40[-1.00,0.80]$ \\
\hline
\end{tabular}

Categorical variables: $\geq 5$ years after surgery by treatment group. Values are given as counts with percentage in parentheses. Between-group differences were tested with Kruskal-Wallis tests. Continuous variables: before and $\geq 5$ years after surgery by treatment group. Values are given as median with interquartile-ranges in square brackets. Between-group differences are tested with the Wilcoxon test. LRYGB, laparoscopic Roux-en-Y gastric bypass; LSG, laparoscopic sleeve gastrectomy; NSAIDs, nonsteroidal anti-inflammatory drugs; PPI, proton pump inhibitor. ${ }^{a}$ Three months or more of prednisolone at $5 \mathrm{mg}$ a day (or the equivalent dose of other steroids).

range. Vitamin $\mathrm{D}_{3}$ levels between $30-50 \mathrm{nmol} / \mathrm{L}$ (inadequate for bone health) were seen postoperatively in $14 / 72$ LSG cases (19.4\%) and 6/70 LRYGB (8.6\%), and <30 $\mathrm{nmol} / \mathrm{L}$ (deficiency) in 4/72 LSG (5.6\%) and 1/70 LRYGB (1.4\%). CTX was measured at follow-up; the median was slightly higher in LRYGB compared to LSG patients but all levels were in a normal range, and a difference between the groups could not be found (Table 1).

\section{Risk Factors for Major Fractures}

For the LRYGB group, the 10-year probability of a major fracture in percent (FRAX score) was 5.4\%, with a 95\% CI of $4.5-6.3 \%$. For the LSG group, the FRAX score for major fracture was higher by a factor of 1.1 , with a $95 \%$ CI of 0.86-1.4. For the LRYGB group, the 10-year probability of a hip fracture in percent (FRAX score) was $0.29 \%$, with a $95 \%$ CI of $0.17-0.45 \%$. For the LSG group, the FRAX score for major fracture was lower by a factor of 0.93 , with a $95 \% \mathrm{CI}$ of $0.47-1.8 \%$. Alcohol consumption $>3$ units/day was more often seen in LRYGB patients. In summary, the FRAX score $>5$ years after surgery was low, and no difference could be found between the two intervention groups.

\section{Discussion}

The goal of this study was to examine long-term changes in body composition after LRYGB and LSG by use of DEXA. In addition, BMD was measured at followup. Our hypothesis was that in LRYGB patients a lower percentage of fat and a lower BMD (reflected by a lower T score at the femoral neck) would be seen compared to LSG at $>5$ years after surgery.

Weight loss in bariatric patients comprises loss of fat mass as well as lean mass. In this trial, after 5 years, loss 
of fat mass and lean mass accounted for around $50 \%$ of total weight loss each. In studies with a shorter follow-up, lean mass loss in relation to fat mass loss is usually lower. However, data on body composition 36 months after surgery measured with DEXA is very limited. Our findings can probably be explained by the pronounced loss of fat mass observed in the first 18 months, after which percentage fat mass seems to increase again [37]. While loss of fat mass is desirable, the general goal is to preserve as much lean mass as possible and achieve a more metabolically favorable body composition. In order to keep lean mass loss as low as possible, a protein-rich protein diet and physical activity - in particular resistance training to promote muscle hypertrophy - is generally recommended, and studies suggest that this strategy is successful in preserving lean mass [38, 39].

The metabolic effect of LRYGB seems to be stronger than LSG resulting in a higher remission rate of e.g. diabetes and dyslipidemia [4-7]. The differences in respect to metabolic outcome might also be mirrored in longterm effects on body composition. Apart from body composition, regional fat distribution is important. A high ratio of trunk-to-leg fat (an "apple" body shape) has a strong association with diabetes and mortality, independent of total fat mass $[3,40]$. In the current trial, we found LRYGB to be slightly more effective in reducing percentage fat, and the trunk-to-leg fat ratio was slightly lower. However, these differences were discreet, no statistical significance was reached comparing the parameters at 6.7 years after surgery, and whether these discreet changes are associated with better metabolic outcome in LRYGB-patients cannot be answered with this trial.

Bone disease in patients who have had bariatric surgery is affected by the catabolic state but also by abnormalities in bone and mineral metabolism related to severe obesity. Mechanisms involved are complex, and the reason for bone loss is probably multifactorial. Proposed mechanisms include skeletal unloading, abnormalities in calciotropic hormones, changes in gut hormones, and impaired intestinal calcium absorption. In this cohort, all patients received vitamin $\mathrm{D}_{3}$ before surgery, and preoperative values were therefore mostly in a normal range. After surgery patients were recommended to take multivitamins as well as vitamin $\mathrm{D}_{3}$. The majority of patients (70-80\%) followed this advice. Nevertheless, $25 \%$ in the LSG group and $10 \%$ in the LRYGB group did not reach the goal of vitamin $\mathrm{D}_{3}$ plasma levels of $50 \mathrm{nmol} / \mathrm{L}$ and might profit from higher doses. In LRYGB patients, calcium supplement was recommended in addition, and regular calcium intake at follow-up was reported in $57 \%$.
In this trial, we found slightly lower median $\mathrm{T}$ scores at the femoral neck in LRYGB patients. While a T score at the femoral neck below -2.5 (indicating osteoporosis) was rarely seen, in both groups a $\mathrm{T}$ score between -1 and -2.5 (osteopenia) was found in around $40 \%$. In the LRYGB group, $28.6 \%$ and in the LSG group $15.3 \%$ of patients had a PTH concentration above $65 \mathrm{pg} / \mathrm{mL}$, while calcium levels were within the normal range. CTX is a degradation product of type 1 collagen and is released into the circulation during bone resorption [41]. Measurement of CTX is considered to be a valid clinical method for determining the balance between bone formation and resorption, and monitoring the response to antiresorptive treatment. In a recent trial, various biomarkers associated with bone turnover were characterized before and up to 24 months after LRYGB [42]. While higher bone turnover was seen up to 1 year after surgery, at the 2 -year follow-up, CTX decreased [42]. In our trial, no elevated CTX in either group could be found, which might indicate that bone turnover occurs in the catabolic phase mainly, and bone metabolism is stabilized thereafter.

PPIs are more often used after LSG, as this intervention is unfortunately often associated with development of gastroesophageal reflux disease [43-45]. Chronic PPI use has been linked to an increased fracture risk, as acid suppression is associated with a reduction in calcium absorption, which can lead to decreased bone density. In this cohort, 38 out of 72 LSG patients (52.8\%) used PPIs, but only 3 out of these (7.9\%) were supplemented with calcium, although the $\mathrm{T}$ score at the femoral neck in this subgroup was below -1.0 in 17/37 (45.9\%) indicating osteopenia.

Some limitations require consideration: in this trial, a nonrandomized cohort was examined. Before surgery, the two groups were comparable in terms of age, sex, and BMI, but diabetes was more often seen in the LRYGB cohort. While body composition was measured both preoperatively and at follow-up, BMD was available in all patients at follow-up only. Although rather unlikely, we cannot rule out any preexisting differences in BMD. FRAX performance of predicting fracture risk in a typical bariatric, morbidly obese study population is limited for several reasons: weight above $125 \mathrm{~kg}$ and age below 40 years are not accepted - which is typically seen in a bariatric cohort. Secondary osteoporosis is defined as presence of - amongst others - chronic malabsorption. Whether bariatric interventions such as LRYGB, which are at least malabsorptive for minerals, should qualify for the presence of chronic malabsorption when using the FRAX score is not defined. 


\section{Conclusions}

In this nonrandomized cohort of LSG and LRYGB patients 6.7 years after surgery, LRYGB led to a slightly lower percentage of fat in body composition and a slightly more favorable body shape (trunk-to-leg fat ratio). No clinically relevant difference in BMD and a low overall fracture risk were found, when following a regime with substitution of multivitamins and vitamin $\mathrm{D}_{3}$ in all patients and calcium in LRYGB patients. While in this cohort the strategy of supplements was followed quite well, deficiencies and bone loss remain an issue after both interventions and should be monitored. Our findings do not support that LSG is safer for bone loss. The possible mineral malabsorption seen in LRYGB might be outweighed by the fact that many LSG patients require PPIs. We strongly recommend a lifelong intake of supplements in all bariatric patients. Patients receiving PPIs (often after LSG) might profit from calcium substitution as well.

\section{Acknowledgments}

We would like to thank Dr. Dieter Menne (Menne Biomed Consulting) for statistical analysis and Ms. Anke Etter-Atlass for technical assistance.

\section{Statement of Ethics}

All procedures performed in this study involving human participants were conducted in accordance with the principles of the Declaration of Helsinki 1964 and its later amendments or comparable ethical standards. Informed consent was obtained from all the individual participants included in the study. The protocol was approved by the Ethics Committee of Northwest and Central Switzerland (EKNZ; approval No. BASEC-2017-01655).

\section{Conflict of Interest Statement}

This investigator-initiated trial was financially supported by the Uniscientia Foundation. Dr. Peterli reports serving as a consultant for Johnson \& Johnson. No other authors reported disclosures. The authors declare no conflicts of interest.

\section{Author Contributions}

Study conception and design: Beglinger, Meyer-Gerspach, Peterli, Peters, Wölnerhanssen; acquisition of data: Bühler, Rast; analysis and interpretation of data: Beglinger, Peterli, Peters, Wölnerhanssen; drafting of manuscript: Bühler, Rast, Wölnerhanssen; critical revision: all authors.

\section{References}

1 Leibel RL, Rosenbaum M, Hirsch J. Changes in energy expenditure resulting from altered body weight. N Engl J Med. 1995 Mar;332(10): 621-8.

2 Goodpaster BH, Thaete FL, Simoneau JA, Kelley DE. Subcutaneous abdominal fat and thigh muscle composition predict insulin sensitivity independently of visceral fat. Diabetes. 1997 Oct;46(10):1579-85.

3 Fox CS, Massaro JM, Hoffmann U, Pou KM, Maurovich-Horvat P, Liu CY, et al. Abdominal visceral and subcutaneous adipose tissue compartments: association with metabolic risk factors in the Framingham Heart Study. Circulation. 2007 Jul;116(1):39-48.

4 Schauer PR, Bhatt DL, Kashyap SR. Bariatric Surgery or Intensive Medical Therapy for Diabetes after 5 Years. N Engl J Med. 2017 May; 376(20): 1997.

5 Yska JP, van Roon EN, de Boer A, Leufkens HG, Wilffert B, de Heide LJ, et al. Remission of Type 2 Diabetes Mellitus in Patients After Different Types of Bariatric Surgery: A Population-Based Cohort Study in the United Kingdom. JAMA Surg. 2015 Dec;150(12): 1126-33.
6 Aminian A, Brethauer SA, Andalib A, Nowacki AS, Jimenez A, Corcelles R, et al. Individualized Metabolic Surgery Score: Procedure Selection Based on Diabetes Severity. Ann Surg. 2017 Oct;266(4):650-7.

7 McTigue KM, Wellman R, Nauman E, Anau J, Coley RY, Odor A, et al.; PCORnet Bariatric Study Collaborative. Comparing the 5-Year Diabetes Outcomes of Sleeve Gastrectomy and Gastric Bypass: The National PatientCentered Clinical Research Network (PCORNet) Bariatric Study. JAMA Surg. 2020 May; 155(5):e200087.

8 Carey DG, Pliego GJ, Raymond RL. Body composition and metabolic changes following bariatric surgery: effects on fat mass, lean mass and basal metabolic rate: six months to one-year follow-up. Obes Surg. 2006 Dec; 16(12):1602-8.

9 Pereira AZ, Marchini JS, Carneiro G, Arasaki $\mathrm{CH}$, Zanella MT. Lean and fat mass loss in obese patients before and after Roux-en-Y gastric bypass: a new application for ultrasound technique. Obes Surg. 2012 Apr;22(4): 597-601.
10 Tamboli RA, Hossain HA, Marks PA, Eckhauser AW, Rathmacher JA, Phillips SE, et al. Body composition and energy metabolism following Roux-en-Y gastric bypass surgery. Obesity (Silver Spring). 2010 Sep;18(9):171824.

11 Moizé V, Andreu A, Rodríguez L, Flores L, Ibarzabal A, Lacy A, et al. Protein intake and lean tissue mass retention following bariatric surgery. Clin Nutr. 2013 Aug;32(4):550-5.

12 Kashyap SR, Bhatt DL, Wolski K, Watanabe RM, Abdul-Ghani M, Abood B, et al. Metabolic effects of bariatric surgery in patients with moderate obesity and type 2 diabetes: analysis of a randomized control trial comparing surgery with intensive medical treatment. Diabetes Care. 2013 Aug;36(8):217582.

13 Schneider J, Peterli R, Gass M, Slawik M, Peters T, Wölnerhanssen BK. Laparoscopic sleeve gastrectomy and Roux-en-Y gastric bypass lead to equal changes in body composition and energy metabolism 17 months postoperatively: a prospective randomized trial. Surg Obes Relat Dis. 2016 Mar-Apr;12(3): $563-70$. 
14 Otto M, Elrefai M, Krammer J, Weiß C, Kienle P, Hasenberg T. Sleeve Gastrectomy and Roux-en-Y Gastric Bypass Lead to Comparable Changes in Body Composition after Adjustment for Initial Body Mass Index. Obes Surg. 2016 Mar;26(3):479-85.

15 Martinaitis L, Tuero C, Fortún Landecho M, Cienfuegos JA, Moncada R, Rotellar F, et al. The long-term benefits of bariatric surgery in elderly and super-obese populations. Rev Esp Enferm Dig. 2019 May;111(5):371-7.

16 Johnell O, Kanis JA. An estimate of the worldwide prevalence and disability associated with osteoporotic fractures. Osteoporos Int. 2006 Dec;17(12):1726-33.

17 Watts NB, Bilezikian JP, Camacho PM, Greenspan SL, Harris ST, Hodgson SF, et al.; AACE Osteoporosis Task Force. American Association of Clinical Endocrinologists Medical Guidelines for Clinical Practice for the diagnosis and treatment of postmenopausal osteoporosis. Endocr Pract. 2010 NovDec;16 Suppl 3:1-37.

18 Reginster JY, Burlet N. Osteoporosis: a still increasing prevalence. Bone. 2006 Feb;38(2 Suppl 1):S4-9.

19 Wright NC, Looker AC, Saag KG, Curtis JR, Delzell ES, Randall S, et al. The recent prevalence of osteoporosis and low bone mass in the United States based on bone mineral density at the femoral neck or lumbar spine. J Bone Miner Res. 2014 Nov;29(11):2520-6.

20 Dyer SM, Crotty M, Fairhall N, Magaziner J, Beaupre LA, Cameron ID, et al.; Fragility Fracture Network (FFN) Rehabilitation Research Special Interest Group. A critical review of the long-term disability outcomes following hip fracture. BMC Geriatr. 2016 Sep; 16(1):158.

21 Sànchez-Riera L, Carnahan E, Vos T, Veerman L, Norman R, Lim SS, et al. The global burden attributable to low bone mineral density. Ann Rheum Dis. 2014 Sep;73(9):163545.

22 Harvey N, Dennison E, Cooper C. Osteoporosis: impact on health and economics. Nat Rev Rheumatol. 2010 Feb;6(2):99-105.

23 Rousseau C, Jean S, Gamache P, Lebel S, MacWay F, Biertho L, et al. Change in fracture risk and fracture pattern after bariatric surgery: nested case-control study. BMJ. 2016 Jul; 354:i3794.
24 Marceau P, Biron S, Lebel S, Marceau S, Hould FS, Simard S, et al. Does bone change after biliopancreatic diversion? J Gastrointest Surg. 2002 Sep-Oct;6(5):690-8.

25 Raoof M, Näslund I, Rask E, Szabo E. Effect of Gastric Bypass on Bone Mineral Density, Parathyroid Hormone and Vitamin D: 5 Years Follow-up. Obes Surg. 2016 May;26(5): 1141-5.

26 von Mach MA, Stoeckli R, Bilz S, Kraenzlin $\mathrm{M}$, Langer I, Keller U. Changes in bone mineral content after surgical treatment of morbid obesity. Metabolism. 2004 Jul;53(7):91821.

27 Kanis JA, Johnell O, Oden A, Johansson H, McCloskey E. FRAX and the assessment of fracture probability in men and women from the UK. Osteoporos Int. 2008 Apr;19(4):38597.

28 Rosen HN, Moses AC, Garber J, Iloputaife ID, Ross DS, Lee SL, et al. Serum CTX: a new marker of bone resorption that shows treatment effect more often than other markers because of low coefficient of variability and large changes with bisphosphonate therapy. Calcif Tissue Int. 2000 Feb;66(2):100-3.

29 R Core Team. R: a language and environment for statistical computing. Vienna: R Foundation for Statistical Computing; 2019.

30 Xie Y. Dynamic documents with $\mathrm{R}$ and knitr. London: Chapman-Hall/CRC; 2013.

31 McShane BB, Gal D, Gelman A, Robert C, Tackett JL. Abandon statistical significance. Am Statist. 2019;73(suppl 1):235-45.

32 Pinheiro JC, Bates DM. Mixed-effects models in S and S-Plus. Berlin: Springer; 2000.

33 Fragoso TM, Bertoli W, Louzada F. Bayesian model averaging: a systematic review and conceptual classification. Int Stat Rev. 2018; 86(1):1-28

34 Raftery AE. Sociological Methodology. Cambridge (Mass.): Blackwells; 1995. pp. 111-96.

35 Raftery A, Hoeting J, Volinsky C, Painter I, Yeung KY. BMA: Bayesian model averaging. Available from: http://CRAN.R-project.org/ package $=$ BMA. 2015

36 Bürkner PC. brms: an R package for Bayesian multilevel models using stan. J Stat Softw. 2017;80(1):1-28.

37 Nuijten MA, Monpellier VM, Eijsvogels TM, Janssen IM, Hazebroek EJ, Hopman MT. Rate and Determinants of Excessive Fat-Free Mass Loss After Bariatric Surgery. Obes Surg. 2020 Aug;30(8):3119-26.
38 Stegen S, Derave W, Calders P, Van Laethem C, Pattyn P. Physical fitness in morbidly obese patients: effect of gastric bypass surgery and exercise training. Obes Surg. 2011 Jan;21(1): 61-70.

39 Stiegler P, Cunliffe A. The role of diet and exercise for the maintenance of fat-free mass and resting metabolic rate during weight loss. Sports Med. 2006;36(3):239-62.

40 Wilson JP, Kanaya AM, Fan B, Shepherd JA Ratio of trunk to leg volume as a new body shape metric for diabetes and mortality. PLoS One. 2013 Jul;8(7):e68716.

41 Vasikaran S, Eastell R, Bruyère O, Foldes AJ, Garnero P, Griesmacher A, et al.; IOF-IFCC Bone Marker Standards Working Group. Markers of bone turnover for the prediction of fracture risk and monitoring of osteoporosis treatment: a need for international reference standards. Osteoporos Int. $2011 \mathrm{Feb}$; 22(2):391-420.

42 Biagioni MF, Mendes AL, Nogueira CR, Leite CV, Gollino L, Mazeto GM. Bariatric RouxEn-Y Gastric Bypass Surgery: Adipocyte Proteins Involved in Increased Bone Remodeling in Humans. Obes Surg. 2017 Jul;27(7):178996.

43 Genco A, Soricelli E, Casella G, Maselli R, Castagneto-Gissey L, Di Lorenzo N, et al. Gastroesophageal reflux disease and Barrett's esophagus after laparoscopic sleeve gastrectomy: a possible, underestimated long-term complication. Surg Obes Relat Dis. 2017 Apr; 13(4):568-74.

44 Felsenreich DM, Kefurt R, Schermann M, Beckerhinn P, Kristo I, Krebs M, et al. Reflux, Sleeve Dilation, and Barrett's Esophagus after Laparoscopic Sleeve Gastrectomy: LongTerm Follow-Up. Obes Surg. 2017 Dec; 27(12):3092-101.

45 Peterli R, Wölnerhanssen BK, Peters T, Vetter D, Kröll D, Borbély Y, et al. Effect of Laparoscopic Sleeve Gastrectomy vs Laparoscopic Roux-en-Y Gastric Bypass on Weight Loss in Patients With Morbid Obesity: The SM-BOSS Randomized Clinical Trial. JAMA. 2018 Jan; 319(3):255-65

46 Ito T, Jensen RT. Association of long-term proton pump inhibitor therapy with bone fractures and effects on absorption of calcium, vitamin B12, iron, and magnesium. Curr Gastroenterol Rep. 2010 Dec;12(6):448-57. 